\title{
Hybrid unified power quality conditioner for power quality enhancement
}

\author{
Djellouli Djoudi, Benoudjafer Cherif, Toumi Toufik, Othmane Abdelkhalek \\ Faculty of Technology, Smart Grids \& Renewable Energies Laboratory, University of Tahri Mohammed, Algeria
}

\begin{tabular}{l}
\hline \hline Article Info \\
\hline Article history: \\
Received Jan 4, 2020 \\
Revised Apr 3, 2020 \\
Accepted Jul 13, 2020 \\
\hline
\end{tabular}

Keywords:

Electrical power quality

Harmonics

Parallel active filter

Series active filter

UPQC

\begin{abstract}
In a low-voltage electrical network, harmonics, reactive power, the current and voltage imbalance, and voltage dips have harmful effects on electrical equipments. To overcome these problems, the hybrid UPQC is proposed. This paper discusses the structure of passive filters, parallel active filters, serial and combines (UPQC) to study the compensation of all types of disturbances likely to appear in the grid. Furthermore, the aim of reducing the size, cost of UPQC is to improve the quality of electric power, making it in compliance with the new regulatory constraints, we proposed the hybrid UPQC which uses passive filters and a combination of active filters. To validate the proposed topology, several sags of source voltage have been applied, at the point of common coupling (PCC). The simulation results from MATLAB/Simulink are discussed to verify the proposed topology.
\end{abstract}

This is an open access article under the CC BY-SA license.

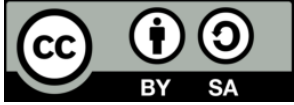

\section{Corresponding Author:}

Djellouli Djoudi,

Department of Electrical Engineering,

Tahri Mohammed University of bechar, Algeria,

The independence street, PB 417 Béchar Algeria.

Email: djellouli.djoudi@yahoo.com

\section{INTRODUCTION}

Power electronics-based systems are the most non-linear loads currently answered. These systems are increasingly causing power grid disturbances, such as harmonic distortions, imbalances, flicker, brief interruptions, voltage dips, and temporary and transient over voltages. In addition, these disturbances can generate nuisance or damage by the assignment of one or more parameters of the voltage of the electrical network, such as the frequency, the amplitude, the symmetry of the three-phase voltages and the shape of the wave. Several solutions for the decontamination of electricity networks have already been proposed in the literature. Those that best meet today's industrial constraints are the Active Shunt Compensator, Series and Active Shunt Combination Series (also known as UPQC). The active passive shunt filters are an indisputable solution only in high voltage transmission lines [1, 2]. However, in all other cases, including the supply of industrial loads and medium and low voltage distribution lines, passive filters encounter multiple difficulties that degrade their efficiency. Active filters have been designed to mitigate the problems of passive filters. However, these active filters used alone have certain drawbacks such as: the low efficiency, the limitation of the high-power bandwidth and the relatively high apparent power of the active filter. [3-5]

Although active filters used alone are useful in some applications, it is sometimes necessary to use hybrid topologies with passive filters and active filters. Hybrid filters treat and mitigate problems with passive and active filters. In addition, the hybrid active filters improve the compensation characteristics of the passive filters which can lead to a reduction of the power of the active filter. Therefore, the hybrid structure arose from the need for improved performance and reduced cost of active filters. Hybrid filters provide 
optimal solution for PQ mitigation with reduced cost, simple design and control with high reliability for PQ improvement [6].

The purpose of this paper is to contribute to improving the performance of current and voltage disturbance compensation from a parallel-series combined structure (UPQC). The active parallel-serial combination, also called "Unified Power Quality Conditioner" (UPQC), results from the combination of the two parallel and serial active filters. Taking advantage of the advantages of the two active filters, the UPQC provides a sinusoidal current and voltage of the electrical network from a disturbed current and voltage of it [7, 16-18].

The document is organized as follows: the general structure the hybrid UPQC in section 2. It also highlights the required units such the identification and regulation methods, hybrid UPQC and control algorithms. Then we will study the hybrid UPQC filter, by simulating the compensation of most current and voltage disturbances will be discussed in section 3. Finally, the document will be completed by the concluding remarks.

\section{CONFIGURATION OF HYBRID UPQC}

To reduce the size of the parallel active filter and its cost, the UPQC is associated with a passive filter whose role is to eliminate the specific frequencies enabling the sizing of the active filter to be reduced, which will compensate for the rest of the disturbances. The general structure of the UPQC Hybrid is composed of two parts: parallel-serial active filters (UPQC) and passive parallel filter as shown in Figure 1. In this configuration, the role of the passive filter is the compensation of the predominant low frequency harmonic currents (h5 and h7) emitted by the polluting load [8].

Passive filters are the simplest and most economical along with the demerits of large size and tuning issues. Hybrid filters provide optimal solution for PQ mitigation with reduced cost, simple design and control with high reliability for PQ improvement. [9]

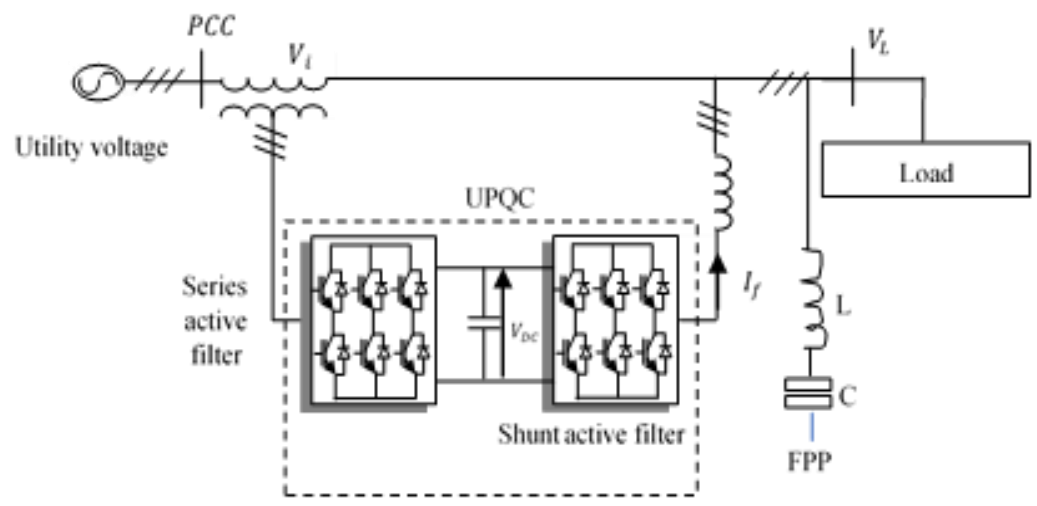

Figure 1. Structure of the hybrid UPQC

\section{CONTROL STRATEGIES}

The application of the Synchronous Reference Frame (SFR) based harmonic extraction, the three currents Ia, Ib and Ic are transformed from the three-phase reference form to the two-phase ds and qs to the reference currents $I_{d}^{S}, I_{q}^{S}$.

$$
\left[\begin{array}{l}
i_{d}^{s} \\
i_{q}^{s}
\end{array}\right]=\sqrt{\frac{2}{3}}\left[\begin{array}{cc}
1-\frac{1}{2} \frac{1}{2} \\
0 \frac{\sqrt{2}}{2}-\frac{\sqrt{2}}{2}
\end{array}\right]\left[\begin{array}{l}
i_{a} \\
i_{b} \\
i_{c}
\end{array}\right]
$$

The currents $\mathrm{i}_{\mathrm{d}}^{\mathrm{s}}$ and $\mathrm{i}_{\mathrm{q}}^{\mathrm{s}}$ transformed to a synchronously rotating frame of reference of de andqe by the vector unit $\cos \omega_{\mathrm{e}}$ and $\sin \omega_{\mathrm{e}}$, as shown below:

$$
\left[\begin{array}{l}
i_{q}^{e} \\
i_{d}^{e}
\end{array}\right]=\left[\begin{array}{c}
\cos \omega_{e}-\sin \omega_{e} \\
\sin \omega_{e} \cos \omega_{e}
\end{array}\right]\left[\begin{array}{l}
i_{q}^{s} \\
i_{d}^{s}
\end{array}\right]
$$


The frequency $\omega_{e}$ is derived from the harmonic order that must be isolated. It is important to note that the direction of the unit vector rotation must be in accordance with the order of the extracted harmonic. Figure 2 shows the transformation of the abc to the reference frame of $d^{e}-q^{e}$.

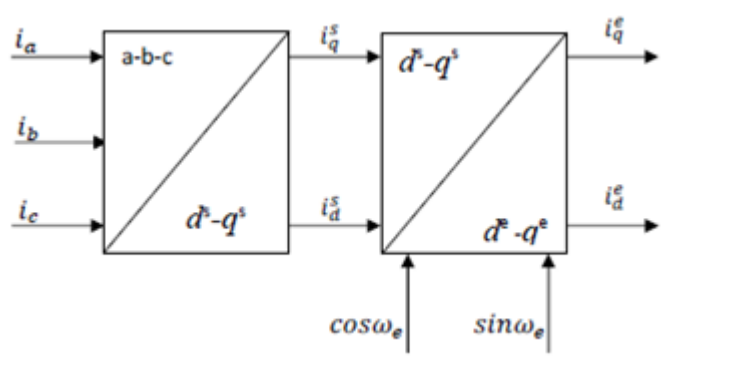

Figure 2. Transformation abc to $\mathrm{d}^{\mathrm{e}}-\mathrm{q}^{\mathrm{e}}$.

In the de-qereference frame the we components appear as quantities of C.C and all other harmonics are transformed to the amounts of C.A. Using a low pass filter, the amount of C.C can be accurately extracted. The current C.C component is now retransforming back to using stationary reference frame:

$$
\begin{aligned}
& {\left[\begin{array}{l}
i_{q}^{s} \\
i_{d}^{s}
\end{array}\right]=\left[\begin{array}{c}
\cos \omega_{e} \sin \omega_{e} \\
-\sin \omega_{e} \cos \omega_{e}
\end{array}\right]\left[\begin{array}{l}
i_{q}^{e} \\
i_{d}^{e}
\end{array}\right]} \\
& {\left[\begin{array}{l}
\mathrm{i}_{\mathrm{a}} \\
\mathrm{i}_{\mathrm{b}} \\
\mathrm{i}_{\mathrm{c}}
\end{array}\right]=\sqrt{\frac{3}{2}}\left[\begin{array}{c}
10 \\
-\frac{1}{2} \frac{\sqrt{3}}{2} \\
-\frac{1}{2}-\frac{\sqrt{3}}{2}
\end{array}\right]\left[\begin{array}{l}
\mathrm{i}_{\mathrm{q}}^{\mathrm{s}} \\
\mathrm{i}_{\mathrm{d}}^{\mathrm{s}}
\end{array}\right]}
\end{aligned}
$$

Since a quantity of DC in the de-qe reference frame corresponds exactly to the harmonic frequency of interest, extracting the amount of DC using the low pass filter ensures the exact synthesis of the harmonic current in the reference frame of abc, Figure 3 shows the arrangement of the filtering.

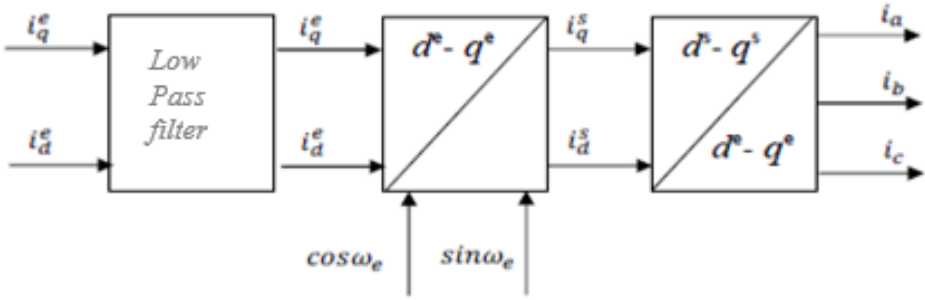

Figure 3. Transformation of de-qe to abc

\subsection{Voltage control of DC bus}

The average voltage across the capacitor must be maintained at a constant value. The causes of its variation are mainly the losses in the switches (in conduction and commutation), in the decoupling inductances Lf and the injection of the fundamental currents during the transient regimes [10-13]. In steady state, the source must provide active power equal to the power demanded by the load. When an active power imbalance occurs in the system, the energy storage capacity must provide the power difference between the network and the load [14-16]. This then results in a variation of the DC voltage across the capacitor supplying the active filter, where regulation is necessary in order to stabilize the voltage across the capacitor. The active power $\mathrm{P}_{\mathrm{f}}$ needed to restore the capacitor voltage to a constant value is given by the expression:

$$
P_{f}=P_{L}-P_{S}
$$


With:

$P_{f}$ : instantaneous power injected by the active filter.

$P_{L}$ : active power consumed by the load.

$P_{s}$ : active power delivered by the source.

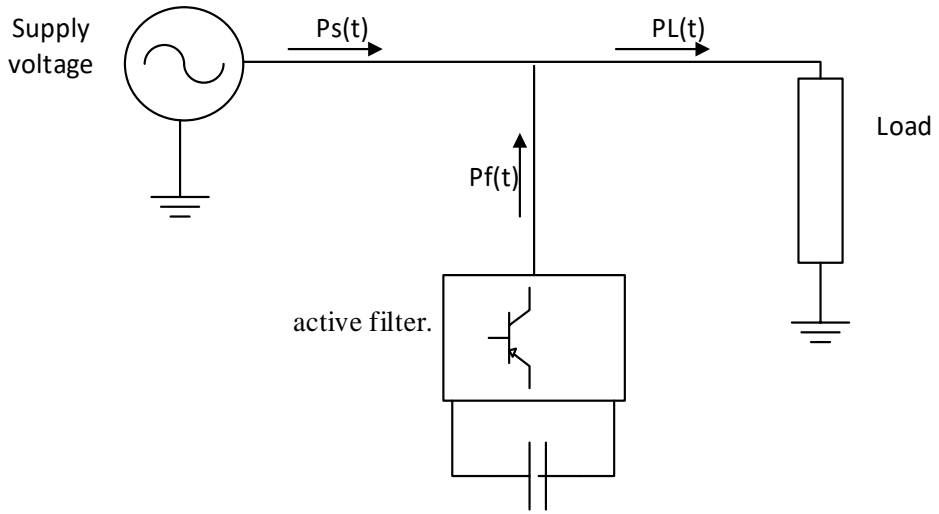

Figure 4. Exchange of power between the network, the load and the filter.

By neglecting the losses in the switches and inductors, the relationship between the active power absorbed by the capacitor and the voltage across it is given by:

$$
P_{c}=\frac{d}{d c}\left(\frac{1}{2} C_{d c} V_{c}^{2}\right)
$$

Note that the relation (6) is nonlinear. For small variations of the $V_{c}$ voltage around its reference $V_{c r e ́ f}$, it can be linearized through the following relationships.

$$
P_{c}=C_{d c} V_{c r e ́ f} \frac{d}{d t}\left(V_{c}\right)
$$

Apply the Laplace transform:

$$
V_{c}(s)=\left(\frac{1}{V_{d c-r e ́ f} C_{d c} s}\right) P_{s}(s)
$$

From the relation (8), and taking into account the proportional controller $K_{c}$, the DC voltage control loop can be represented by the diagram in Figure 5 . The choice of the $K_{c}$ parameter will aim to obtain a minimum response time so as not to harm the dynamics of the active filter [17]. In order to obtain the signal $P_{\text {ré } f}$ one has the choice between a proportional regulator and a proportional integral regulator.

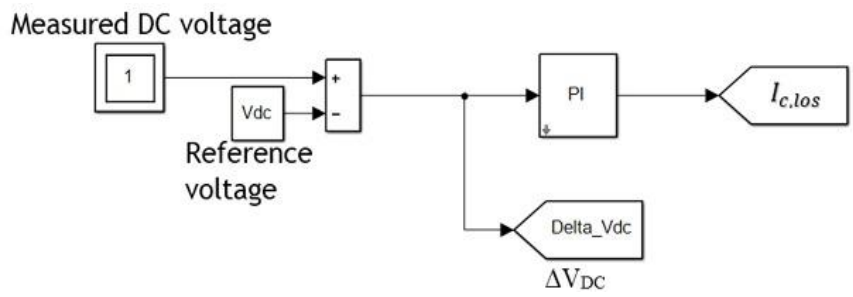

Figure 5. DC voltage regulation loop

We have the transfer function of the closed loop: 


$$
\frac{V_{c}^{2}}{V_{c r e ́ f}^{2}}=\frac{\frac{K_{p}}{C_{d c}} s+\frac{2 K_{i}}{C_{d c}}}{s^{2}+\frac{2 K p}{C_{d c}}+\frac{2 K_{i}}{C_{d c}}}
$$

By arranging them:

$$
\frac{V_{c}^{2}}{V_{c r e ́ f}^{2}}=\frac{\omega^{2}+2 \omega \varepsilon s}{s^{2}+2 \omega \varepsilon s+\omega^{2}}
$$

So:

$$
\omega^{2}=\frac{2 K_{i}}{C_{d c}} \text { and } \varepsilon=K_{p} \sqrt{\frac{1}{2 C_{d c} K_{i}}}
$$

To have a good damping coefficient of the closed-loop system, we have chosen $\varepsilon=0.7$

$$
K_{i}=\frac{C_{d c} \omega^{2}}{2} \text { and } K_{p}=\varepsilon \sqrt{2 C_{d c} K_{i}}
$$

\subsection{Series converter control}

Since the series filter is considered to be a compensation voltage generator, the load current causes voltage drops in the output filter and therefore a larger difference between the set point and the output voltage.To compensate for the error produced by the LRC filter, the voltage loop can be closed and based on the filter model, develop voltage correctors $[18,19]$. So, the contribution $I_{L}$ will be eliminated during the designation of the PI controller of the voltage control loop, and therefore the model of the output filter will be modified to have a structure of two nested loops, one internal current and the other external voltage as shown in Figure 6 [20-22].

\subsection{Shunt converter control}

The regulator design is typically connected to the speed specification required response of the closed loop or, also, the maximum error to follow respecting the reference signal. These specifications can be specifications of the bandwidth and phase margin of the closed loop. So, it is necessary to determine the parameters $\mathrm{Kp}$ and $\mathrm{Ki}$ to guarantee these necessities. To quickly have an estimation on the sought values, we suppose that we can approximate the transfer function to the cutoff frequency $\omega \mathrm{CL}=2 \pi \mathrm{fCL}$ to the following expression [23-25]. Shunt filter control loop is shown in Figure 7.

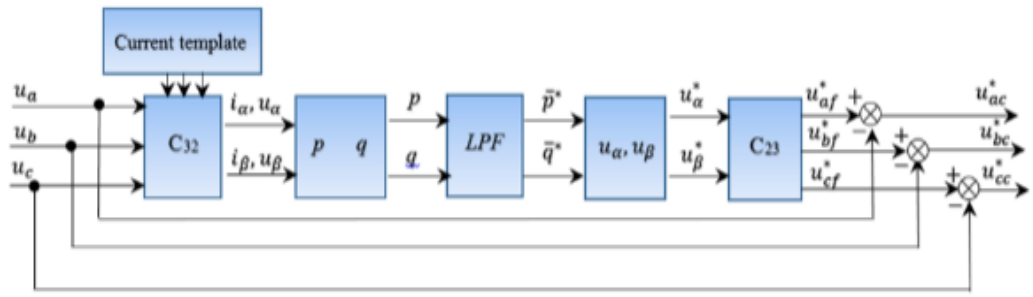

Figure 6. Two-loop control scheme (internal current and external voltage)

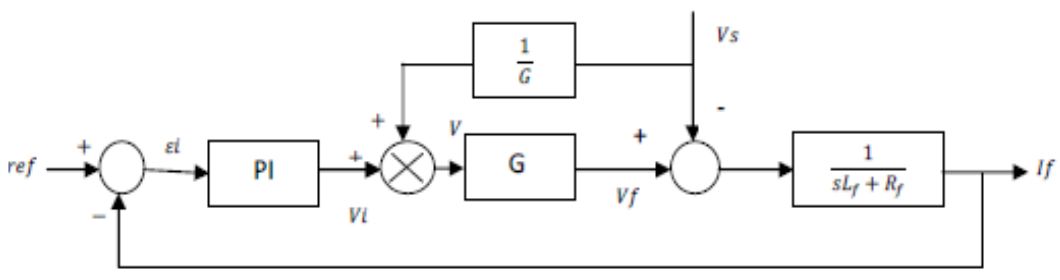

Figure 7. Shunt filter control loop 


\section{RESULTS AND DISCUSSION}

The overall modeling of the structure, allowed studying the hybrid UPQC for the harmonic compensation and the reduction of the parallel active filter sizing through simulations on MATLAB/Simulink.Two resonant passive filters tuned at the frequency $250 \mathrm{~Hz}$ (h5) and $350 \mathrm{~Hz}(\mathrm{~h} 7)$ respectively are connected in parallel with the UPQC load side. The proposed hybrid UPQC model is simulated by MATLAB/Simulink Figure 8 . The system parameters considered for this study are given in Table 1.

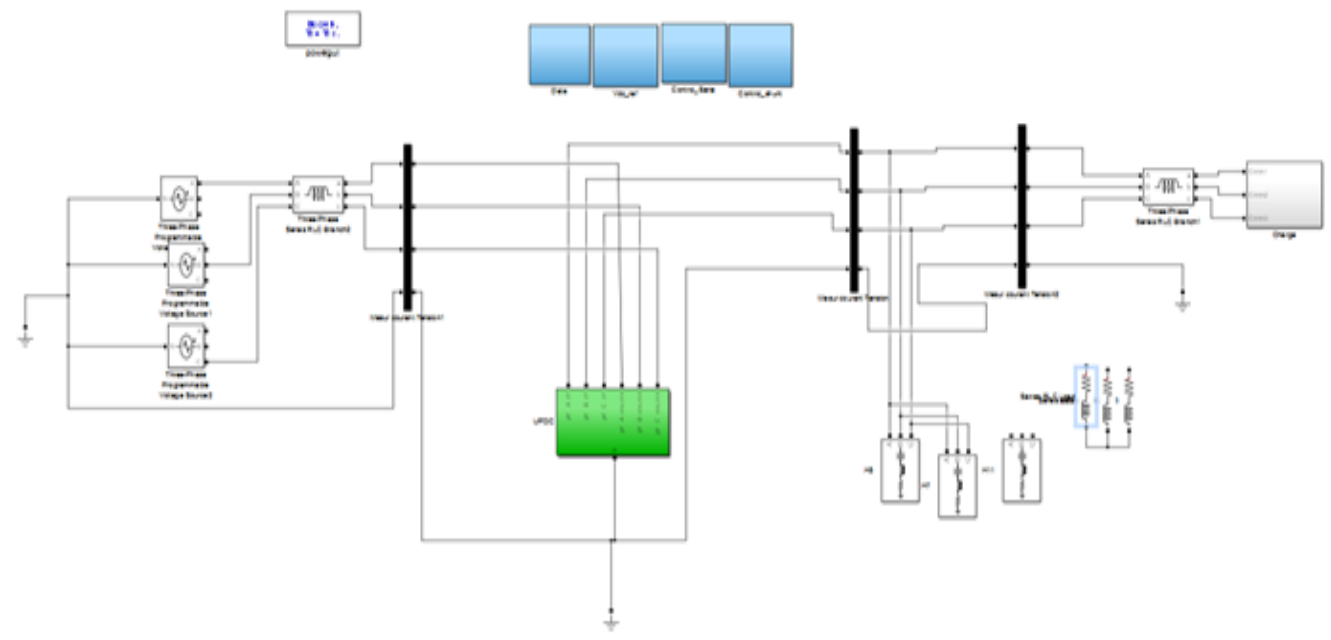

Figure 8. MATLAB/Simulink modelled system.

Table 1. System parameters

\begin{tabular}{cc}
\hline System parameters & value \\
\hline Power system & $300 \mathrm{~V}$ \\
Grid voltage & $50 \mathrm{~Hz}$ \\
Frequency & $0,01+j 10 e^{-6} \Omega$ \\
Line impedance & $\mathrm{R}_{\mathrm{a}}=40_{-} ; \mathrm{La}=0.01 \mathrm{mH} ;$ \\
Nonlinear load & $\mathrm{R}_{\mathrm{b}}=10_{-} ; \mathrm{Lb}=0.01 \mathrm{mH} ;$ \\
& $\mathrm{R}_{\mathrm{c}}=13_{-} ; \mathrm{Lc}=0.01 \mathrm{mH} ;$ \\
UPQC & $735.6 \mathrm{~V}$ \\
DC link voltage & $0.0087 \mathrm{~F}$ \\
DC link capacitor & $12 \mathrm{KHz}$ \\
PWM switching & \\
Connection filter of shunt filter & \\
KP-shunt $=0.6183 ;$ KI-shunt $=757.4515 / \mathrm{sec}$ & \\
Connection filter of series filter $(\mathrm{RLC})$ & \\
KI-current $=0.0427 / \mathrm{sec} ; \mathrm{KP}-$ curnt $=52.4701$ & \\
KI-voltage $=1.9950103 / \mathrm{sec} ; \mathrm{KP}-$ voltage $=0.5690$ &
\end{tabular}

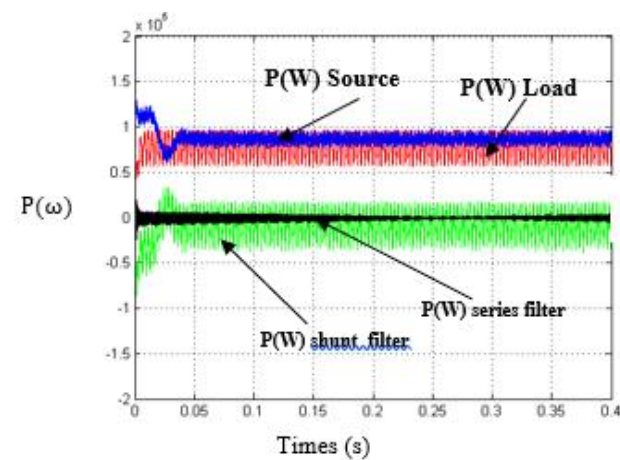

Figure 9. Active power without passive filter

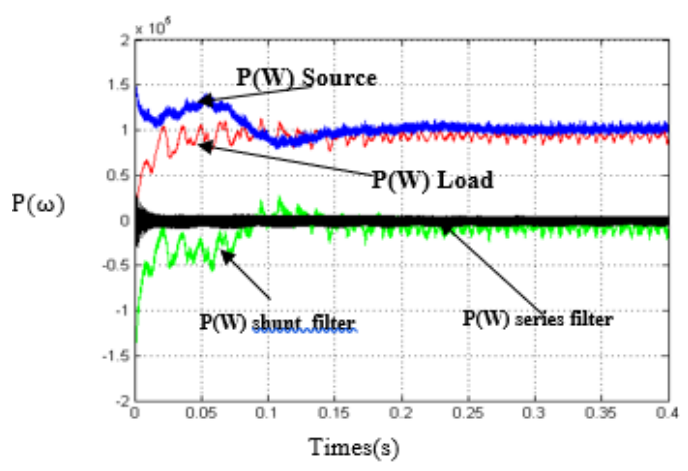

Figure 10. Active power with passive filter 


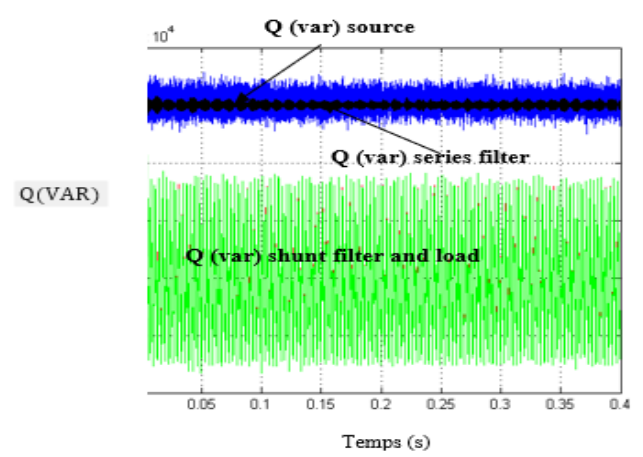

Figure 11. Reactive power without passive filter

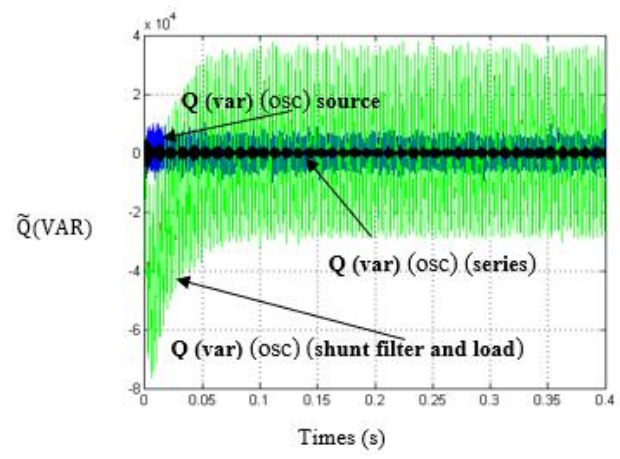

Figure 13. Reactive power (osc) without passive filter

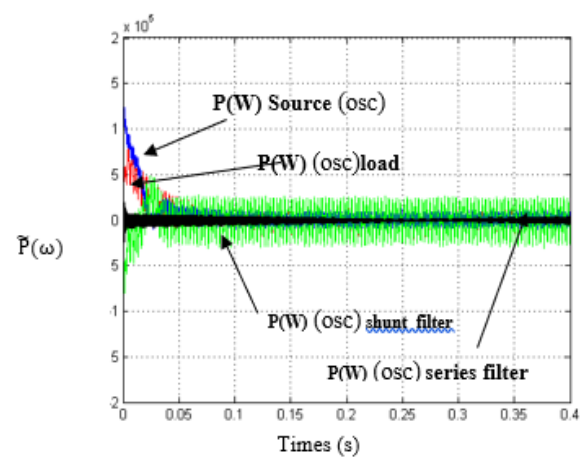

Figure 15. Active power(osc) without passive filter

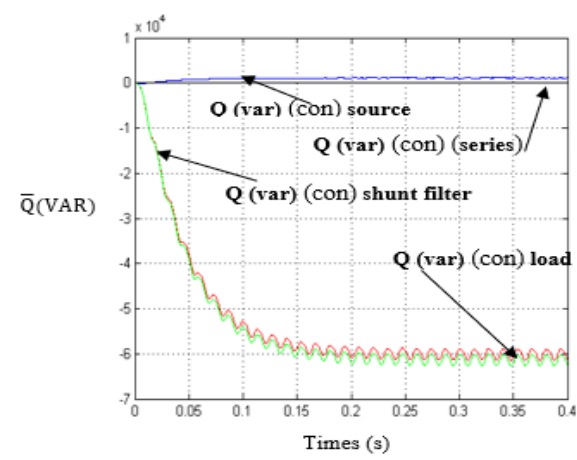

Figure 17. Reactive power (con) without passive filter

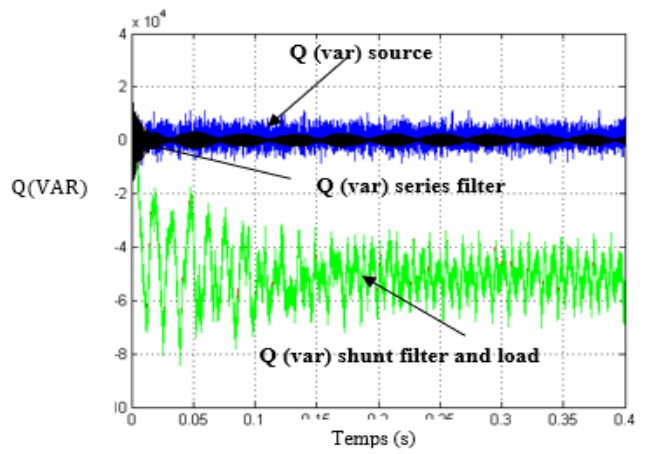

Figure 12. Reactive power with passive filter

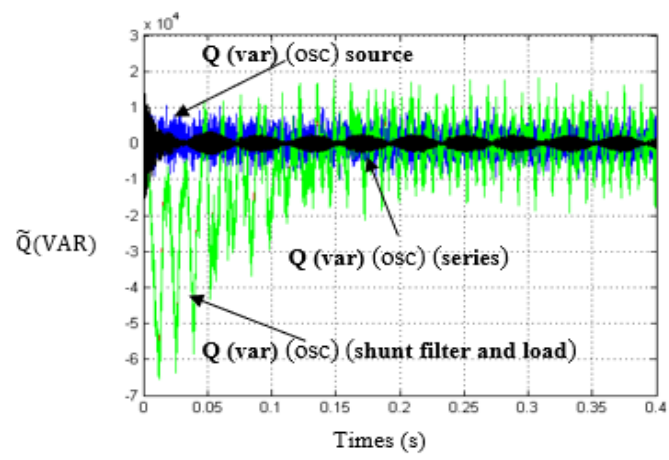

Figure 14. Reactive power (osc) with passive filter

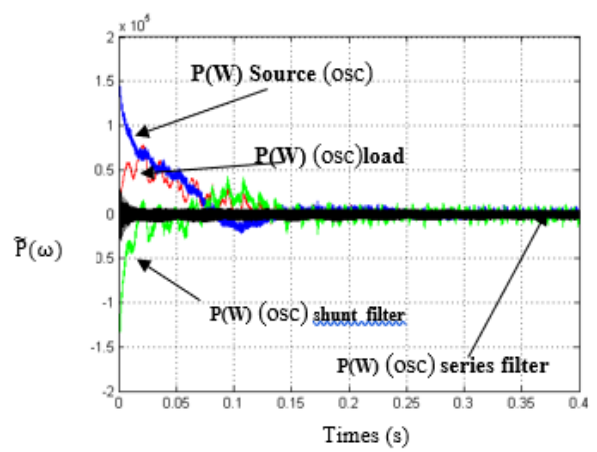

Figure 16. Active power(osc) with passive filter

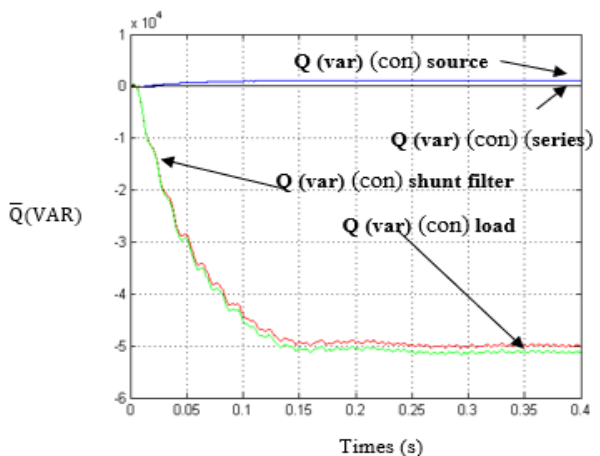

Figure 18. Reactive power (con) with passive filter 


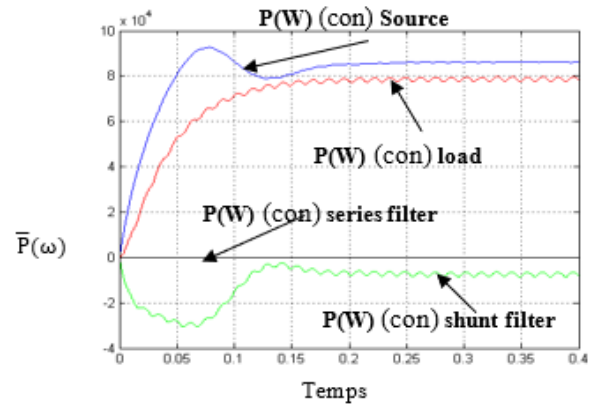

Figure 19. Active power (con) without passive filter

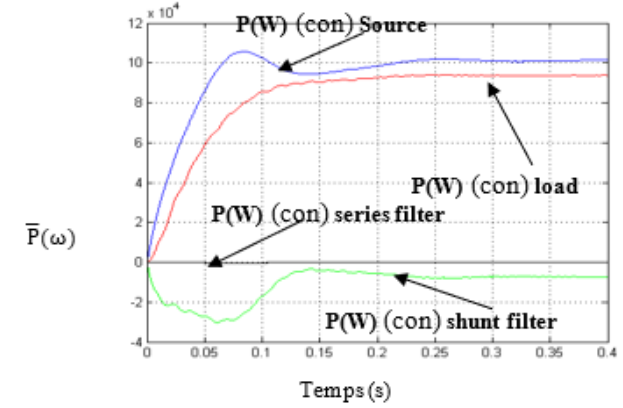

Figure 20. Active power(con) with passive filter

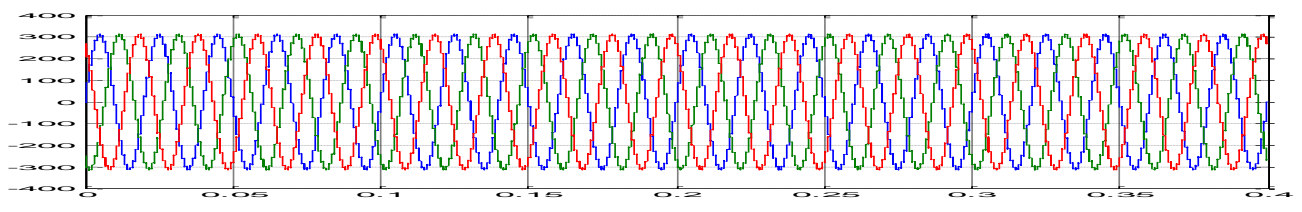

Figure 21. load voltage

త্
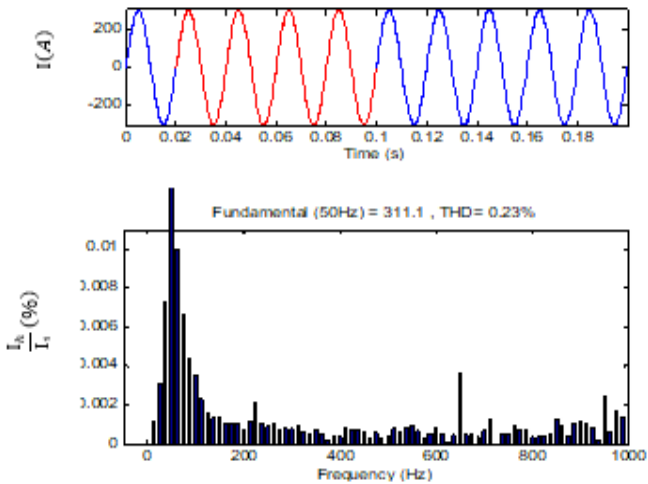

Figure 22. Source current with filter passif
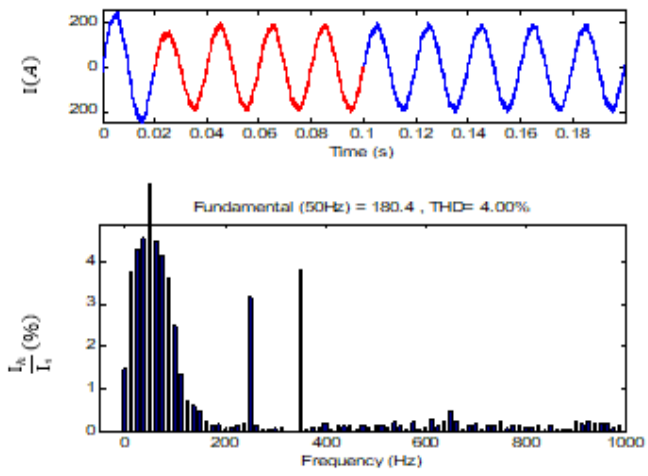

Figure 23. Source current without passive filter

\section{CONCLUSION}

In this article After validating the parallel and serial active filters, an active parallel-serial combination and a passive filter (UPQC hybrid) were studied in order to validate the simultaneous operation of these three filters. This combination could benefit from the common operation of some elements of these three parts (the voltage source and the capacitor recharge). The structure chosen for the UPQC hybrid, offering the possibility, via the parallel active filter, to recharge the energy storage capacitors online. A reduction in the size of these capacitors has been achieved by the passive filter. Thus, it can be said that the resonant passive filter $(\mathrm{h} 5+\mathrm{h} 7)$ further improved the operation of the parallel active filter of the UPQC and further decreased its apparent power. It has become very reasonable. The UPQC Hybrid performs better than the conventional UPQC as it has less apparent power than the UPQC Classic. The only drawback of the parallel hybrid filter is the risk of resonance with the impedance of the network but the use of a low value inductance between the resonant passive filter and the UPQC reduces this risk. The UPQC hybrid provides sinusoidal current and voltage from the power grid from a disturbed current and voltage thereof. Sizing has decreased and the cost is reduced.

\section{ACKNOWLEDGEMENTS}

The authors are thankful to the General Direction of Scientific Research and Technological Development, DGRSDT for providing a research grant. 


\section{REFERENCES}

[1] ShafiuzzamanK. Khadem, MalabikaBasu.Conlon "A comparative analysis of placement and control of UPQC in DG integrated grid connected network," Sustainable Energy, Grids and Networks, 2016.

[2] H. Akagi, A. Nabae, S. Atoh, "Control strategy of active power filters using multiple voltage-source PWM converters", IEEE Trans. on Industry applications, vol. IA-22, pp. 460-465, 1986.

[3] Om Prakash Mahela, Abdul Gafoor Shaik, "Topological aspects of power quality improvement techniques: A comprehensive overview," Renewable and Sustainable Energy Reviews, Vol. 58, pp. 1129-1142, 2016.

[4] S. Bhattacharya, A. Veltman, D. M. Divan and R. D. Lorenz, "Flux based active filter controller," in Conf. Rec. IEEE-IAS Annu. Meeting, pp. 2483-2491, 1995.

[5] Singh B, Venkateswarlu P. "A simplified control algorithm for three phase, four-wire unified power quality conditioner," Journal of Power Electronics, Vol. 10, No. 1, pp. 91-96, 2010.

[6] Nishant Patnaik, Anup Kumar Panda, "Performance analysis of a 3 phase 4 wire UPQC system based on PAC based SRF controller with real time digital simulation," Electrical Power and Energy Systems, Vol. 74, pp. 212$221,2016$.

[7] Ravi Nath Tripathi, Alka Singh, Tsuyoshi Hanamoto, "Design and control of LCL filter interfaced grid connected solar photovoltaic (SPV) system using power balance theory," Electrical Power and Energy Systems, Vol. 69, pp. 264-272, 2015.

[8] S. Samal, P K. Hota, "Wind Energy Fed UPQC System for Power Quality Improvement", Bulletin of Electrical Engineering and Informatics, vol. 7, pp. 495-504, September 2018.

[9] A. Javadi, A. Hamadi, L. Woodward, and K. Al-Haddad, "Experimental investigation on a hybrid series active power compensator to improve power quality of typical households," IEEE Trans. Ind. Electron., vol. 63, no. 8, pp. 4849-4859, Aug 2016.

[10] B. Singh, K. Al-Haddad and A. Chandra, "A review of active filters for power quality improvement", IEEE Transactions on Industrial Electronics, vol. 46, no. 5, pp. 960-971, 1999.

[11] Miguel Aguirre, Hernan Couto, Maria Inés Valla, "Analysis and simulation of a hydrogen based electric system to improve power quality in distributed grids," International journal of hydrogen energy, Vol. 37, pp. 14959-14965, 2012.

[12] Toufik Toumi, Ahmed Allali, Othmane Abdelkhalek, Abdallah Ben Abdelkader, Abdelmalek Meftouhi, Mohammed Amine Soumeur, "PV Integrated single-phase dynamic voltage restorer for sag voltage, voltage fluctuations and harmonics compensation," International Journal of Power Electronics and Drive Systems (IJPEDS), vol. 11, no. 1, pp547-554, 2020.

[13] L. P. Kunjumuhammed, Mahesh K. Mishra "A control algorithm for single-phase active power filter under nonstiff voltage source," IEEE Trans. Power Electron., Vol. 21, no 3, pp. 822-825; May 2006.

[14] V. M. Mishra, et al., "Novel Optimization Technique for PI Controller Parameters of ac/dc PWM Converter using Genetic Algorithms," International Journal of Power Electronics and Drive System (IJPEDS), vol. 2, no. 2, pp. 151-159, 2012.

[15] K. V. R. Reddy, et al., "Advance Technology in Application of Four Leg Inverters to UPQC," International Journal of Power Electronics and Drive System (IJPEDS), vol. 7, no. 4, pp. 1153-1160, 2016.

[16] K. R. Rao and K. S. Srikanth, "Improvement of Power Quality using Fuzzy Logic Controller in Grid Connected Photovoltaic Cell using UPQC," International Journal of Power Electronics and Drive System (IJPEDS), vol. 5, no. 1, pp. 101-111, 2014.

[17] P. Ajitha and D. Jananisri, "Voltage Sag Mitigation and Load Reactive Power Compensation by UPQC," Bulletin of Electrical Engineering and Informatics, vol. 3, no. 2, pp. 109-112, 2014.

[18] P Ajitha, D Jananisri, "Voltage Sag Mitigation and Load Reactive Power Compensation by UPQC," Bulletin of Electrical Engineering and Informatics, vol. 3, No. 2, pp. 109-112, June 2014.

[19] N. Patnaik, A. K. Panda, "Performance analysis of a 3 phase 4 wire UPQC system based on PAC based SRF controller with real time digital simulation" Electrical Power and Energy Systems, vol. 74, pp. 212-221, 2016.

[20] A. Hamadi, S. Rahmani and K. Al-Haddad, "A Hybrid Passive Filter Configuration for VAR Control and Harmonic Compensation," IEEE Transactions on Industrial Electronics, vol. 57, no. 7, pp. 2419-2434, 2010.

[21] A. Bhattacharya, C. Chakraborty and S. Bhattacharya, "Shunt compensation," IEEE Industrial Electronics Magazine, vol. 3, no. 3, pp. 38-49, 2009.

[22] R. Beres, X. Wang, M. Liserre, F. Blaabjerg and C. Bak, "A Review of Passive Power Filters for Three-Phase GridConnected Voltage-Source Converters," IEEE Journal of Emerging and Selected Topics in Power Electronics, vol. 4, no. 1, pp. 54-69, 2016.

[23] R. N. Tripathi, A. Singh, T. Hanamoto, "Design and control of LCL filter interfaced grid connected solar photovoltaic (SPV) system using power balance theory," Electrical Power and Energy Systems, vol. 69, pp. 264 272,2015

[24] S. Devassy and B. Singh, "Design and Performance Analysis of Three-Phase Solar PV Integrated UPQC," IEEE Transactions on Industry Applications, vol. 54, no. 1, pp. 73-81, 2018.

[25] D. D, S. Bugata and K. J, "A control strategy on power quality improvement in consumer side using custom power device," Indonesian Journal of Electrical Engineering and Computer Science, vol. 15, no. 1, pp. 80-87, 2019. 